\title{
Stability and tremor in the fingers associated with cerebellar hemisphere and cerebellar tract lesions in
}

\section{man}

\author{
J D COLE, H I PHILIP, E M SEDGWICK \\ From the Wessex Neurological Centre, Southampton, UK
}

SUMMARY Stability and tremor in the fingers were assessed by a new technique in patients with unilateral cerebellar syndromes. In 11 patients with unilateral cerebellar hemisphere lesions tremor was observed with either clear tremor at 5-7 Hz or prolongation of the tremor profile out to $11 \mathrm{~Hz}$. In 10 patients with unilateral cerebellar lesions associated with ipsilateral past-pointing there was an asymmetry in finger stability. Compared with normal subjects there was a significant decrease in stability contralateral to the lesion, while the ipsilateral side's stability was not different from normal. In patients with high brain stem lesions at the level of cranial nerves VII and above, tremor had frequencies of 5-7 Hz. In those with lower brain stem lesions, often with long tract signs as well, the frequencies of tremor were faster, 8-11 Hz, which may reflect damage to cerebellar inflow tracts. A broad if not specific correlation was found between clinical condition, site of lesion and finger stability and tremor.

The classical study of the clinical syndromes associated with cerebellar damage has remained that of Gordon Holmes, ' who studied a population with localised cerebellar lesions caused by low velocity rifle injuries. His descriptions of hypotonia, reflex change, fatigue, movement disorder and disturbances of coordination have remained definitive.

More recently clinical testing of cerebellar functions, at least in the limbs, has focused on movements of more proximal joints often under visual control, such as finger-nose ataxia and dysdiadochokinesis. ${ }^{23}$ These movements are ballistic in the sense that their speed and accuracy do not depend to any large extent upon continuously updated peripheral feedback and indeed they may involve feed forward. ${ }^{4}$ Similarly emphasis has been placed on the proximal origin in a limb of the tremor of cerebellar lesions, ${ }^{2}$ and this distribution has been used to distinguish it from the more distal tremors such as essential tremor etc.

The present work has investigated the effect of unilateral cerebellar lesions on stability and tremor in the index finger. The patients were asked to maintain

Address for reprint requests: Dr J D Cole, Wessex Neurological Centre, Southampton SO9 4XY, UK

Received 15 March 1988.

Accepted 15 May 1988 as accurately as possible small forces, $0.049-0.78 \mathrm{~N}$, $(5-100 \mathrm{~g} \mathrm{wt})$, on a typewriter key connected to a strain gauge, with a movement allowed of only $0 \cdot 1-1.0 \mathrm{~mm}$. Visual feedback was allowed via a milliammeter dial but could be withdrawn. The aim was to determine whether cerebellar lesions have an effect on movement of the fingers as well as on the more proximal joints. Some of the results have been communicated to the Physiological Society in abstract form. ${ }^{56}$

\section{Methods}

The technique, data collection and analysis were similar to that used in the previous paper.'

All patients had been admitted to the Wessex Neurological Centre, and had been examined by a consultant neurologist or neurosurgeon. In addition at the time of the task they were examined by one of us, (JDC). Consent for this study was obtained from the hospital ethical committee and from the patients themselves.

The patients with common clinical signs or symptoms have been grouped together. These have then been related to the CT appearances and their pattern of finger tremor and stability. The site of the lesion from CT did not always relate to the clinical picture, not surprisingly in view of the anatomical closeness of functional tracts in the cerebellum and brain stem.

a. Cerebellar hemisphere lesions and tremor.

Six of the patients had tissue diagnoses of tumour, including 

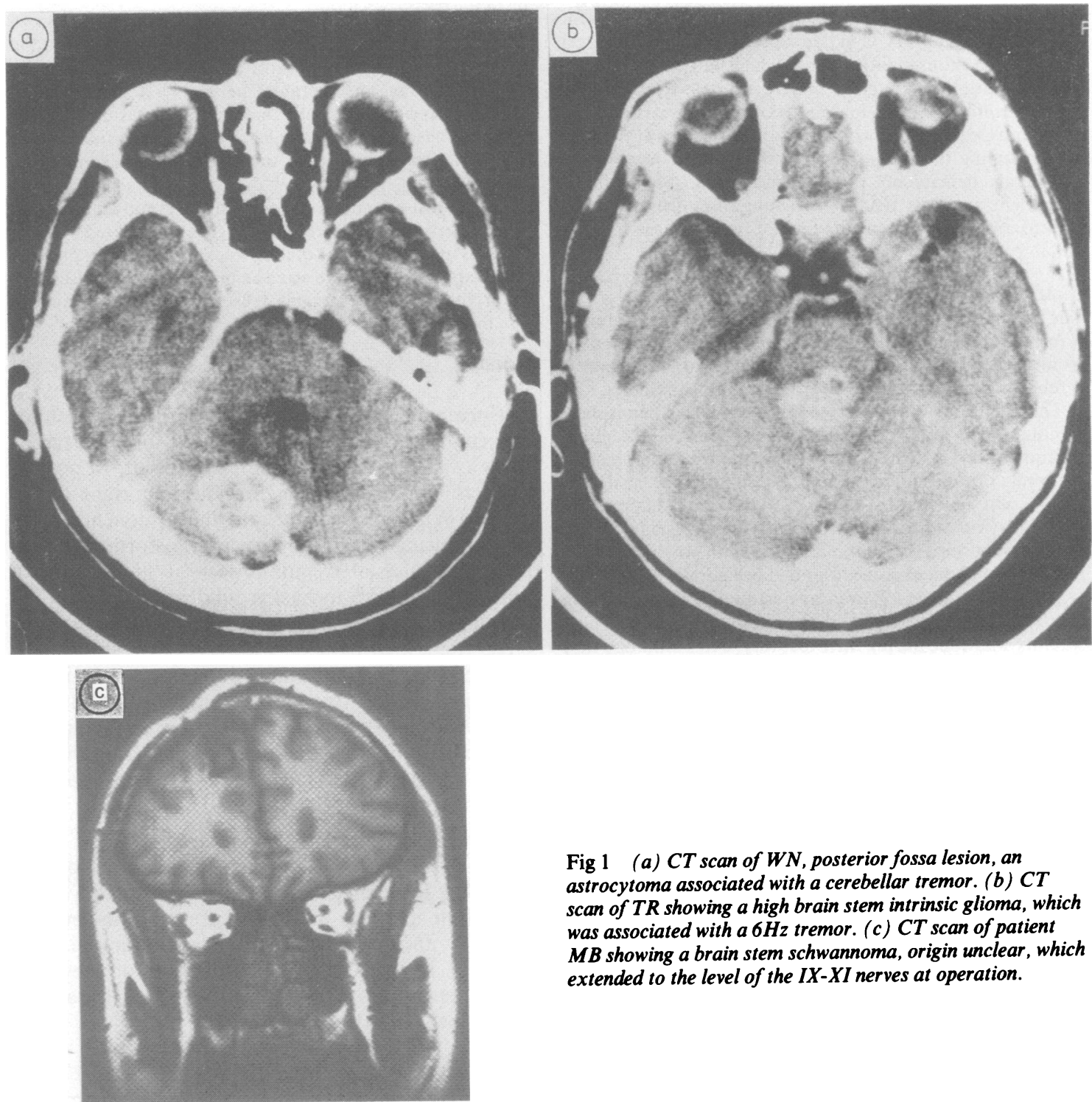

Fig 1 (a) CT scan of $W N$, posterior fossa lesion, an astrocytoma associated with a cerebellar tremor. (b) $C T$ scan of TR showing a high brain stem intrinsic glioma, which was associated with a $6 \mathrm{~Hz}$ tremor. (c) CT scan of patient $M B$ showing a brain stem schwannoma, origin unclear, which extended to the level of the IX-XI nerves at operation.

Table 1 Patients in group b. Clinical diagnoses and signs when tested

\begin{tabular}{|c|c|c|}
\hline Initials age (yr) & Diagnosis & Signs \\
\hline $\begin{array}{l}\text { MM } 17 \\
\text { PC } 46 \\
\text { JP } 34\end{array}$ & $\begin{array}{l}\text { left cerebellar hemisphere AVM } \\
\text { left cerebellar hemisphere AVM } \\
\text { left cerebellar hemisphere medulloblastoma }\end{array}$ & $\begin{array}{l}\text { left sided past pointing } \\
\text { left sided past pointing } \\
\text { left sided weakness grade } 4+\text { past pointing, slow finger } \\
\text { movement, dysdiadochokinesis }\end{array}$ \\
\hline $\begin{array}{l}\text { AS } 49 \\
\text { PS } 64 \\
\text { WG } 45 \\
\text { RB } 50 \\
\text { MB } 48 \\
\text { VA } 67\end{array}$ & $\begin{array}{l}\text { left acoustic schwannoma } \\
\text { left cerebellar secondary } \\
\text { dermoid cyst right brain stem } \\
\text { spinocerebellar degeneration } \\
\text { brainstem schwannona } \\
\text { left cerebellar hemisphere AVM }\end{array}$ & $\begin{array}{l}\text { VIII nerve hearing loss } \\
\text { left past pointing, slow finger movement } \\
\text { none } \\
\text { past pointing left }>\text { right } \\
\text { past pointing left, pyramidal weakness left, hemisensory } \\
\text { truncal ataxia, past pointing and slow finger movement } \\
\text { Lt }>\text { Rt }\end{array}$ \\
\hline RW 39 & left cerebellar hemisphere and peduncle AVM & none \\
\hline
\end{tabular}


medulloblastoma, astrocytoma and secondary deposits, (for an example see fig la). One had had an infarct and the rest were arteriovenous malformations which had bled. The signs at presentation in four cases were of raised intracranial pressure with papilloedema and headache. Dysarthria and nystagmus was seen in two patients. In five cases at the time of performing the tremor test the signs had reduced to an ipsilateral deficit of dysdiadochokinesis, slow finger movement and past pointing. In four cases there were no clinical cerebellar signs at the time of testing finger stability and in particular no tremor.

\section{b. Minimal cerebellar signs during movement.}

The ten patients in this group had a variety of diagnoses, (table 1). They had all recovered from a catastrophic event or from surgery to be left with either no signs or unilateral cerebellar signs of past pointing or dysdiadochokinesia.

The diagnoses were in three cases cerebellar hemisphere tumours, in four cerebellar hemisphere bleeds from angiomas, two extrinsic brain stem masses, one acoustic neuroma, one dermoid cyst, and one spinocerebellar degeneration with unilateral signs. In most cases they had presented with symptoms of raised pressure such as headache and had papilloedema or had presented with an intracranial bleed. Their surgical procedures had been done, for example ventricular drainage followed by posterior fossa exploration or they had recovered from the bleed. Testing of finger stability was done during their recovery. Thus although they had presented with florid signs of cerebellar lesions, post operatively these signs had resolved.

\section{c. High brain stem lesions.}

In this group were six patients who had, in addition to mild cerebellar signs, long tract pyramidal signs and higher cranial nerve deficits. Two patients had acoustic schwannomas and three brain stem gliomas in the pons at the level of or above the outflow of the VIIth cranial nerve, (for an example see fig 1b). They presented with a variety of clinical symptoms including diplopia, facial nerve weakness and altered facial sensation. Cerebellar ataxia was complained of by four and weakness due to pyramidal deficit by one. Long tract signs were present in two patients. Ipsilateral cerebellar signs were found in two patients, comprising dysdiadochokinesis and slow finger movements and so were absent in three patients. d. Low brain stem lesions.

Finger stability was measured in nine patients in whom the pathology was either demonstrated to be low in the pons at the level of the lower cranial nerves, (VIIIth nerve and below), or in whom clinically that was the level suggested but in whom the lesion, for example a CVA, was not amenable to localisation by radiological imaging, (for an example see fig lc).

The clinical symptoms and signs in this group are shown in table 2. However a difference in this group compared with the others is in the frequency of long track involvement. In seven out of eight patients there was a hemiparesis or a hemisensory disturbance. This presumably reflects the closeness of structure in the low pons.

\section{Results}

The normal result of the task is that the finger cannot be kept completely stable; there are small perturbations away from the desired force output. In normal subjects there was no significant left : right asymmetry. ${ }^{7}$ When plotted out into their frequency components using the Fast Fourier Transform the maximal amplitude of tremor is seen at $1-3 \mathrm{~Hz}$ with a gradual falling off to background levels by $6 \mathrm{~Hz}$. In normal subjects no additional peak was seen above $6 \mathrm{~Hz}$, (fig 2). In patients with cerebellar lesions two sorts of tremor abnormality have been seen in the frequency profile. In one the tailing off of tremor frequencies by about $6 \mathrm{~Hz}$ did not occur, giving high frequencies above that but not always a specific and separate peak, whilst in other cases there was a clear additional peak.

\section{a. Cerebellar hemisphere lesions and tremor.}

In this group are 11 patients with lesions of one cerebellar hemisphere with associated tremor. There were four patients in whom tremor was evident clinically and indeed one in whom it was the main problem. In the others the tremor was only evident during performance of the task. Some of the patients overlapped with those in group b.

Table 2 Clinical signs and tremor in patients with low pontine lesions

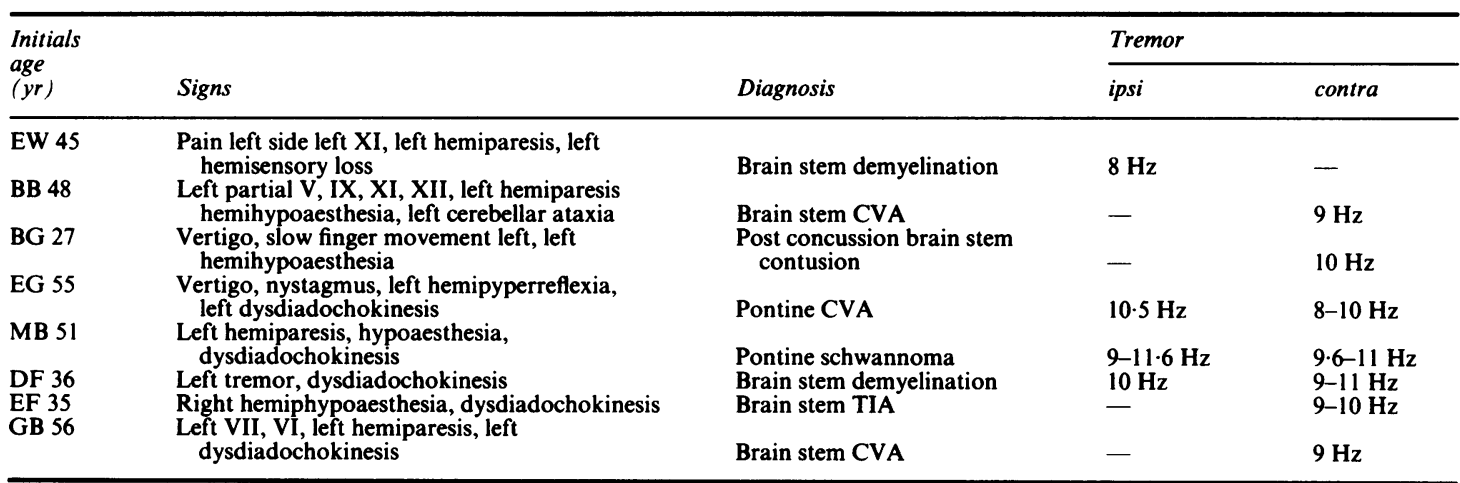



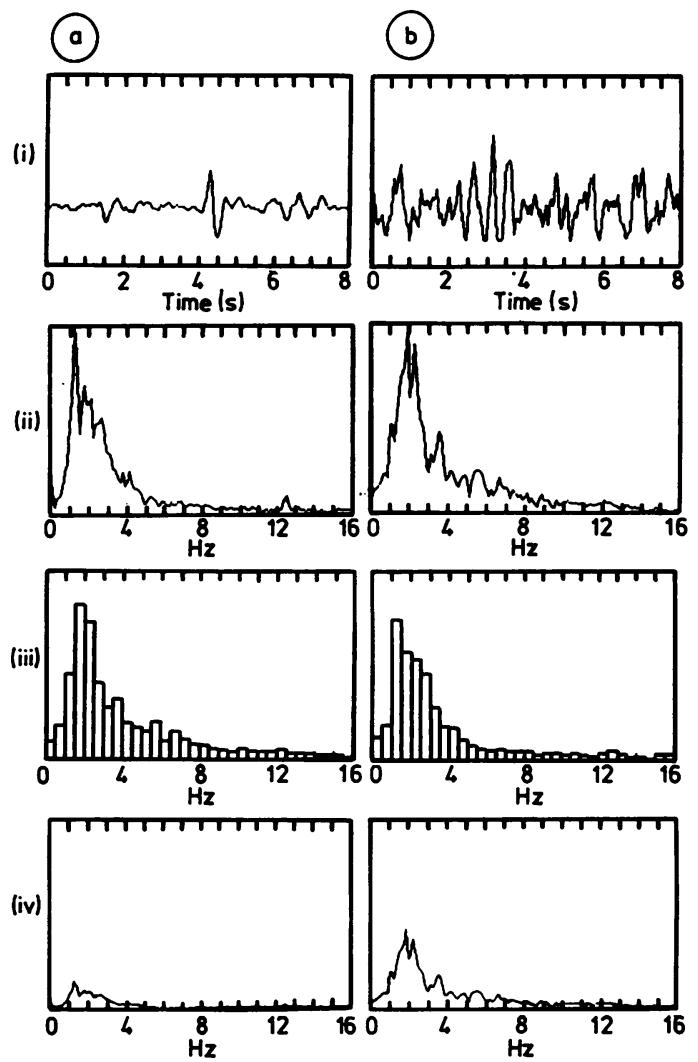

Fig 2 Normal tremor profile, right index fingers eyes open at sensitivities, $a .100 \mathrm{~g}$ and $b .10 \mathrm{~g}$. The box figures, (i) shows the raw data of tremor over 8 s., (ii) the frequency profile of tremor expressed as an amplitude density, with full deflection taken up by the maximum amplitude of tremor. The ordinate shows frequency $1-16 \mathrm{~Hz}$, the abscissa amplitude of tremor in $\mathrm{g} \mathrm{s}^{-1}$ on a linear scale, (iii) histogram of tremor amplitude with $0.5 \mathrm{~Hz}$ bins and (iv) an amplitude density of tremor with absolute scale. (Full deflection in (a) $50 \mathrm{~g} \mathrm{~s}^{-1}$, in (b) $5 \mathrm{~g} \mathrm{~s}^{-1}$ ). In the subsequent FFT figures the bottom two box figures have been omitted.
The frequencies of tremor observed are shown in table 3, and two examples of the tremor in fig 3. Although there was no clinical tremor in most of these cases it was evident during the test at sensitivities of $100 \mathrm{~g} \mathrm{wt}$. and accentuated at lower forces. The effect of performing the task with eyes shut was variable; in some cases it enhanced the tremor whilst in others it reduced it. Tremor was observed at frequencies from $5 \mathrm{~Hz}$ to $10 \mathrm{~Hz}$ ipsilateral and contralateral to the lesion and signs. In the four cases in which the tremor was evident clinically its frequencies were $5-7 \mathrm{~Hz}$, although in one case subclinical tremor was seen at $5 \mathrm{~Hz}$. Higher frequency tremor often appeared as a prolongation of the amplitude density's tail out to $10 \mathrm{~Hz}$, (fig 3a). No patient had both a $5-\mathrm{Hz}$ tremor and a prolonged tail out to $10 \mathrm{~Hz}$.

\section{b. Minimal cerebellar signs during movement.}

Ten patients were examined with unilateral past pointing or dysdiadochokinesis from cerebellar or cerebellar outflow tract lesions. None of these had cerebellar tremor during testing. In all cases their stability was better on the side of their lesion, (for an example see fig 4). However, when the amplitudes of tremor derived from the FFT are compared with normal controls it became apparent that the effect was an increased instability on the side opposite to the lesion, with ipsilateral stability not significantly different from normal, (table 4).

The effect of eye closure in normal controls was to improve stability by $31 \%$, reflecting the underdamping effect of the phase lag between strain gauge and milliammeter needle movement. In these patients the improvement ipsilaterally was $38 \%$ and contralaterally $28 \%$. There was a tendency for the improvement in stability to be increased more on the side ipsilateral to the lesion, suggesting that with reduced cerebellar function the remaining motor apparatus is underdamped in a visually dominated task. This might be the finger equivalent of limb past pointing.

Table 3 Frequencies of tremor with cerebellar hemisphere lesions.

\begin{tabular}{|c|c|c|c|c|}
\hline \multirow[b]{2}{*}{ Initials } & \multirow[b]{2}{*}{ Signs } & \multirow[b]{2}{*}{ Clinical tremor } & \multicolumn{2}{|c|}{ Tremor frequencies } \\
\hline & & & ipsi- & contralateral \\
\hline JP & $\begin{array}{l}\text { Nystagmus, left past pointing, slow fast finger movement, } \\
\text { dysdiadochokinesis, left sided weakness }\end{array}$ & none & - & $8 \mathrm{~Hz}$ \\
\hline $\begin{array}{l}\text { PM } \\
\text { RH } \\
\text { RC } \\
\text { DV } \\
\text { LF } \\
\text { RV } \\
\text { WN } \\
\text { RN } \\
\text { MM } \\
\text { PC }\end{array}$ & $\begin{array}{l}\text { Right hand clumsy, no past pointing, etc } \\
\text { None } \\
\text { Dysarthria, nystagmus, past pointing finger ataxia } \\
\text { None } \\
\text { Nystagmus, truncal ataxia } \\
\text { Dysdiadochokinesis, left finger ataxia } \\
\text { Dysdiadochokinesis } \\
\text { None } \\
\text { Right intention tremor, right finger ataxia } \\
\text { Left past pointing }\end{array}$ & $\begin{array}{l}\text { yes } \\
\text { none } \\
\text { yes } \\
\text { none } \\
\text { none } \\
\text { none } \\
\text { yes } \\
\text { none } \\
\text { yes } \\
\text { none }\end{array}$ & $\begin{array}{l}5 \cdot 5 \mathrm{~Hz} \\
5 \mathrm{~Hz} \\
5 \mathrm{~Hz} \\
6-8 \mathrm{~Hz} \\
9-10 \mathrm{~Hz} \\
8 \mathrm{~Hz} \\
7 \cdot 7 \mathrm{~Hz} \\
8 \mathrm{~Hz} \\
7 \mathrm{~Hz} \\
6 \mathrm{~Hz}\end{array}$ & $\begin{array}{l}- \\
\overline{7} \mathrm{~Hz} \\
6-8 \mathrm{~Hz} \\
8-10 \mathrm{~Hz} \\
6 \mathrm{~Hz} \\
\overline{6} \mathrm{~Hz} \\
\overline{-} 10 \mathrm{~Hz}\end{array}$ \\
\hline
\end{tabular}


(i)
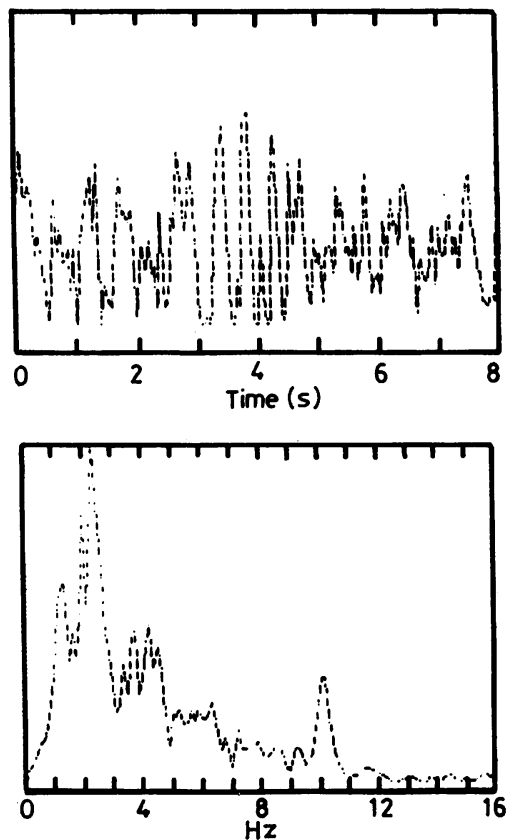

(b)
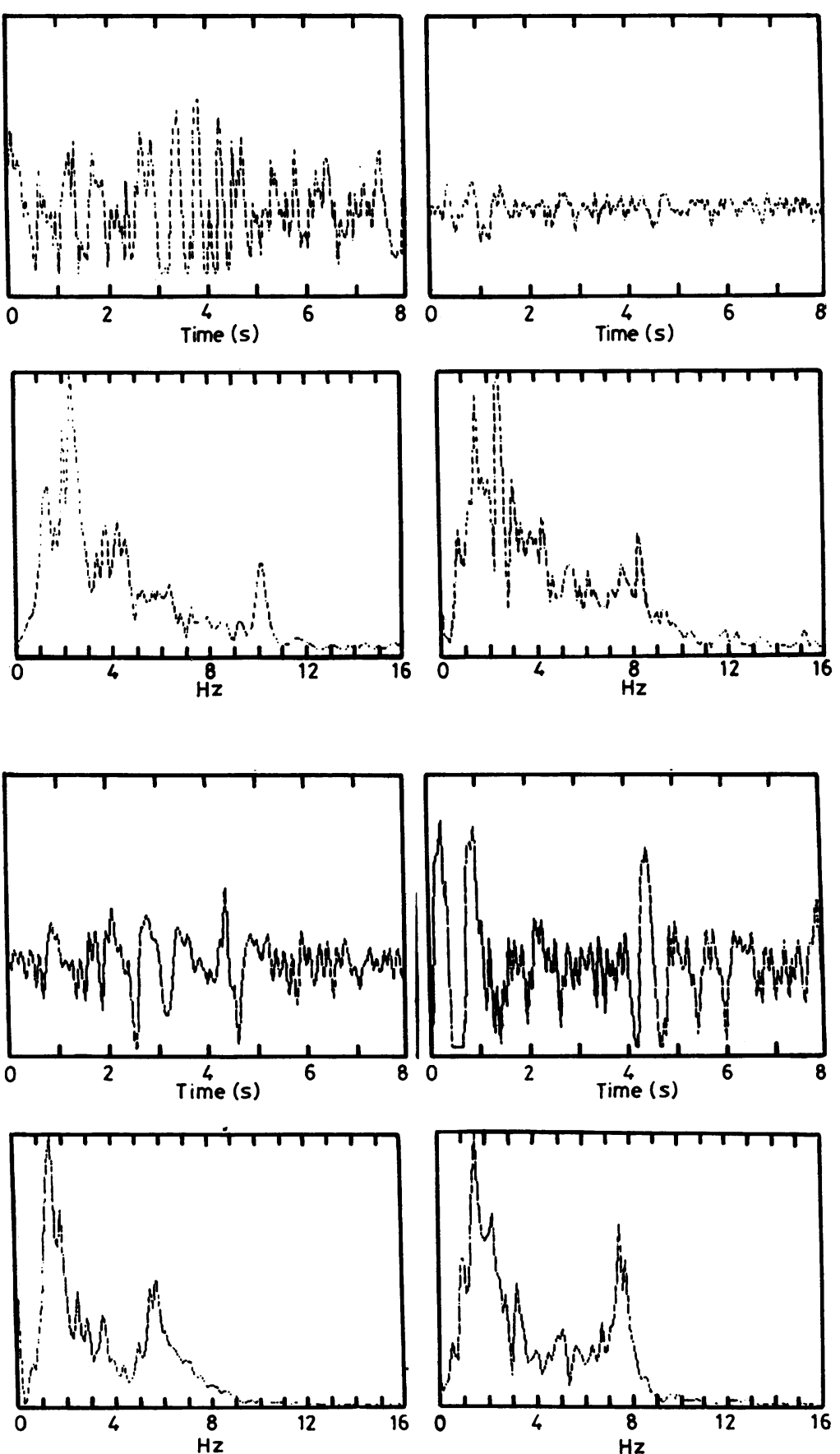

Fig 3 Tremor associated with cerebellar hemisphere lesions. (a) LF post-operative, left cerebellar hemispherectomy. (i) right index finger eyes shut, sensitivity $5 \mathrm{~g}$. note peak at 10 $\mathrm{Hz}$. Tremor amplitude at $2.38 \mathrm{~Hz} 1.28 \mathrm{~g}$. (ii) right index finger eyes open, sensitivity $100 \mathrm{~g}$. tremor out to $8 \mathrm{~Hz}$ with a peak at $8.3 \mathrm{~Hz}$. Tremor amplitude at $2.50 \mathrm{~Hz} 5.46 \mathrm{~g}$. (b) $\mathrm{RC}$ left cerebellar secondary. (i) pre-operation right index finger, sensitivity $100 \mathrm{~g}$. Tremor amplitude at $1.50 \mathrm{~Hz} 12.8 \mathrm{~g}$. (ii) post-operation left index finger, sensitivity $100 \mathrm{~g}$. Tremor amplitude at $1.50 \mathrm{~Hz} 10.7 \mathrm{~g}$. 
(a)

(i)

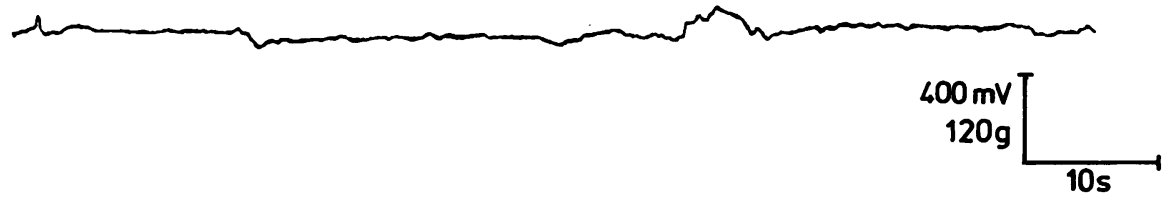

(ii)

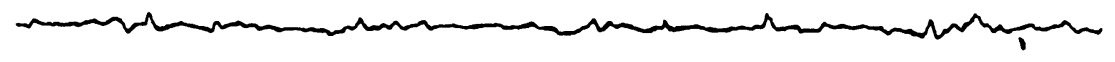

(iii)

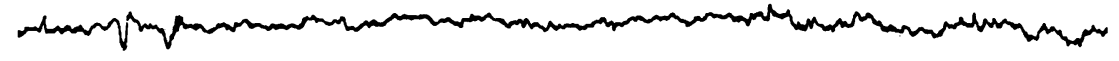

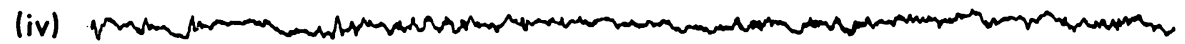

(b)

(i)
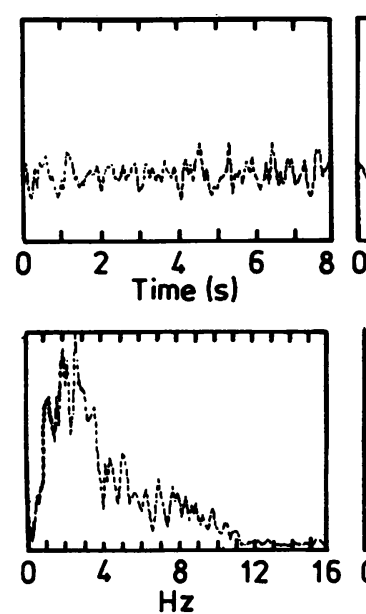

(ii)

(iii)
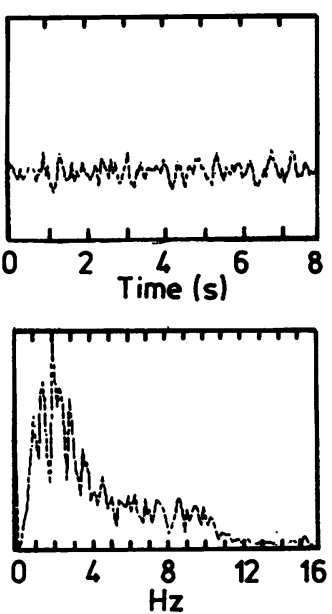
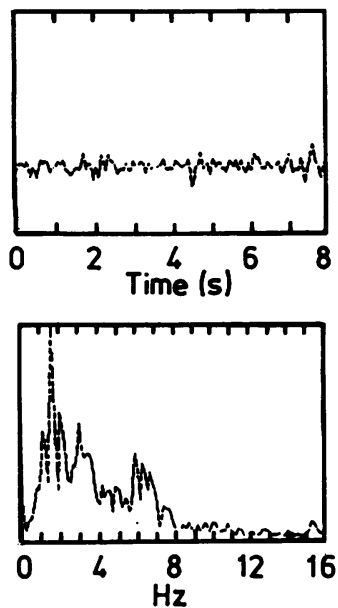

(iv)
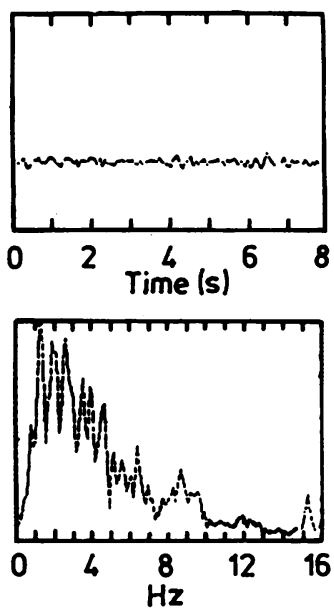

Fig 4 Stability associated with cerebellar hemisphere lesion. PC post-operation left cerebellar hemispherectomy. Sensitivity $100 \mathrm{~g}$. (a) XY plot. (i) left index finger eyes shut, (ii) left index finger eyes open, (iii) right index finger eyes shut, (iv) right index finger eyes open. (b) FFT amplitude density. (i) right index finger eyes open. Tremor amplitude at $2.63 \mathrm{~Hz}, 6.54 \mathrm{~g}$, (ii) right index finger eyes shut. Tremor amplitude at $2.0 \mathrm{~Hz}, 5.76 \mathrm{~g}$, (iii) left index finger eyes open. Tremor amplitude at $1.63 \mathrm{~Hz}, 2.89 \mathrm{~g}$, (iv) left index finger eyes shut. Tremor amplitude at $1.38 \mathrm{~Hz}, 1.85 \mathrm{~g}$. Note the prolonged tail of tremor on the right side and the small tremor peak at 6-7 $\mathrm{Hz}$ on the left.

c. High brain stem lesions.

The frequency of tremor found was 5-7 Hz, usually ipsilateral more than contralateral, (for examples see fig 5 and table 5). The lateralisation is of course complicated by expansion of a lesion on one side leading to compression on the other.

Two patients were investigated with classical red nucleus tremor. The frequency measured was $2-3 \mathrm{~Hz}$, with a gross tremor evident, (fig 6). The gross tremor was reduced by a factor of 10 when the task was performed with the eyes shut. One case had a cerebellar infarct and the other a brain stem infarct. Thus as Marsden commented, ${ }^{8}$ these gross tremors do not necessarily involve the red nucleus in the pons, but presumably may effect the relevant pathway elsewhere. 
Table 4 Stability in group 3, patients with unilateral past pointing.

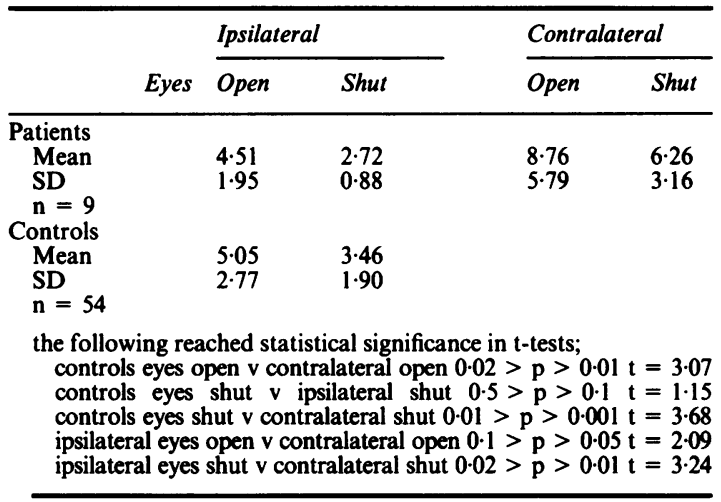

\section{d. Low brain stem lesions.}

It is important to note that in only one of these patients was the tremor clinically evident. Even in patient MB with clear fast tremor there was no tremor detected during routine clinical tests. In several of the patients peformance of the task at sensitivity of $100 \mathrm{~g}$ did not show any abnormality, but stressing them to perform the task at $25 \mathrm{~g}$ or $10 \mathrm{~g}$ did reveal significant amounts of tremor.

The tremor frequencies were fast, between 8 and $12 \mathrm{~Hz}$, (table 2 and fig 7). They could be ipsilateral or contralateral to the lesion, although in this group the problems were seldom clearly one sided. Even in those (a)
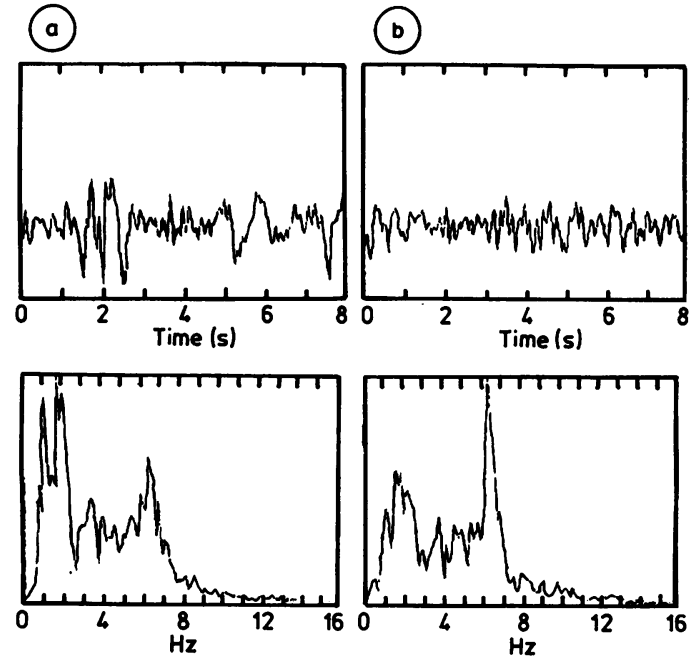

Fig $5 R C$, right acoustic schwannoma after operation. Sensitivity $100 \mathrm{~g}$. (a) right index finger eyes open. Tremor amplitude at $1.75 \mathrm{~Hz} 13.3 \mathrm{~g}$. (b) right index finger eyes shut. Tremor amplitude at $6.38 \mathrm{~Hz} 11.5 \mathrm{~g}$. Note the enhancement of the tremor when the task was performed with the eyes shut.

which were on CT scan, there was suggestion of contralateral compression. In some cases there was a failure of the normal frequency profile of tremor to return to baseline by $6 \mathrm{~Hz}$ and it "stayed up" until $10 \mathrm{~Hz}$ or so, whilst in other cases there was a clear tremor frequency separate from the background.

Table 5 Tremor associated with higher brain stem lesions.

\begin{tabular}{|c|c|c|c|c|}
\hline \multirow[b]{2}{*}{ Initials } & \multirow[b]{2}{*}{ Diagnosis } & \multirow[b]{2}{*}{ Clinical signs } & \multicolumn{2}{|l|}{ Tremor } \\
\hline & & & ipsi- & contralateral \\
\hline JR & glioma & $\begin{array}{l}\text { nystagmus, left V left VII, cerebellar and } \\
\text { pyramidal signs }\end{array}$ & $6 \mathrm{~Hz}$ & $5 \mathrm{~Hz}$ \\
\hline $\begin{array}{l}\text { EF } \\
\text { PB } \\
\text { MA } \\
\text { MV } \\
\text { KF }\end{array}$ & $\begin{array}{l}\text { acoustic neuroma } \\
\text { acoustic neuroma } \\
\text { acoustic neuroma } \\
\text { glioma } \\
\text { AVM }\end{array}$ & $\begin{array}{l}\text { nystagmus right diplopia } \\
\text { left VIII, left VII, left dysdiadochokinesia } \\
\text { right V, right VII, dysdiadochokinesia } \\
\text { left hemisensory symptoms } \\
\text { right V, diplopia, right hemisensory } \\
\text { symntoms }\end{array}$ & $\begin{array}{l}5 \mathrm{~Hz} \\
\overline{7} \mathrm{~Hz} \\
5-6 \mathrm{~Hz} \\
-\end{array}$ & $\begin{array}{l}5 \mathrm{~Hz} \\
6 \mathrm{~Hz} \\
- \\
\overline{6} \mathrm{~Hz}\end{array}$ \\
\hline IF & glioma & diplopia, ataxia right $>$ left & $5 \mathrm{~Hz}$ & $5 \mathrm{~Hz}$ \\
\hline
\end{tabular}

Table 6 Frequency of tremor in patient MB against sensitivity of strain gauge

\begin{tabular}{|c|c|c|c|c|}
\hline \multirow[b]{3}{*}{ Sensitivity g.wt } & \multicolumn{4}{|l|}{ Tremor } \\
\hline & \multicolumn{2}{|l|}{ Right } & \multicolumn{2}{|l|}{ Left } \\
\hline & frequency $\mathrm{Hz}$ & amplitude g.wt & frequency $\mathrm{Hz}$ & amplitude g.wt \\
\hline $\begin{array}{l}80 \\
25 \\
5 \\
2.5\end{array}$ & $\begin{array}{r}11.6 \\
10.7 \\
10.6 \\
9.5\end{array}$ & $\begin{array}{r}2 \cdot 7 \\
3 \cdot 1 \\
7 \cdot 2 \\
20 \cdot 3\end{array}$ & $\begin{array}{r}11.0 \\
10.8 \\
10.8 \\
9.9\end{array}$ & $\begin{array}{r}2 \cdot 1 \\
6 \cdot 9 \\
16 \cdot 7 \\
10 \cdot 3\end{array}$ \\
\hline
\end{tabular}


(a)
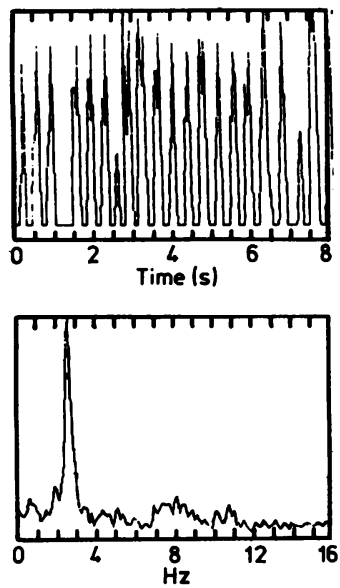

Fig 6 Two examples of red nucleus tremor. (a) $R B$ brainstem CVA. Right index finger eyes open. Sensitivity 100 $\mathrm{g}$, tremor amplitude at $2.63 \mathrm{~Hz} 96.2 \mathrm{~g}$. (b) WC right cerebellar infarct. Right index finger eyes open. Sensitivity $100 \mathrm{~g}$, tremor amplitude at $2.38 \mathrm{~Hz} 77.2 \mathrm{~g}$. Note the large amplitude of tremor. (a)

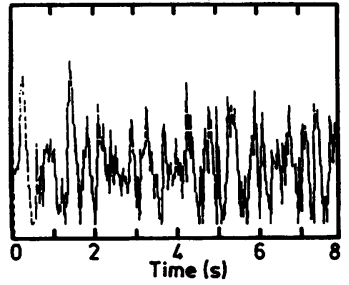

(b)
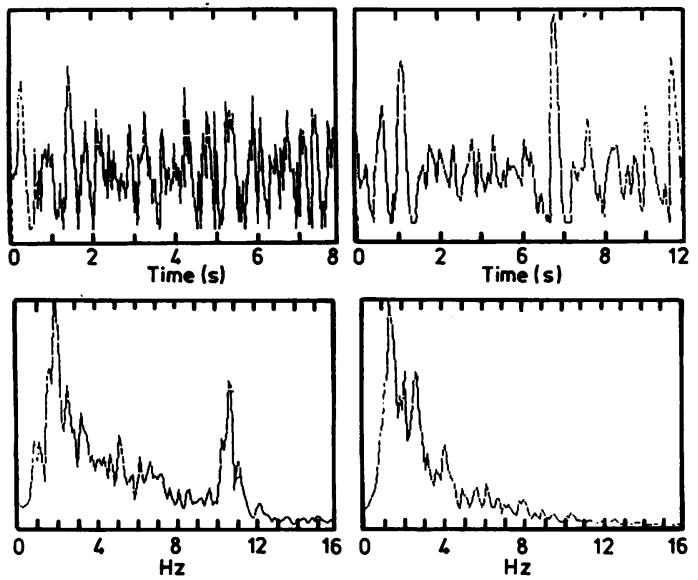

Fig 8 Effect of operative decompression on tremor in patient $M B$. (a) Pre-operation left index finger. Sensitivity $25 \mathrm{~g}$, tremor amplitude at $2 \cdot 38 \mathrm{H} 7.0 \mathrm{~g}$. (b) Post-operation left index finger. Sensitivity $25 \mathrm{~g}$, tremor amplitude at 1.38 $\mathrm{Hz} \mathbf{7} \cdot 37 \mathrm{~g}$.

(b)
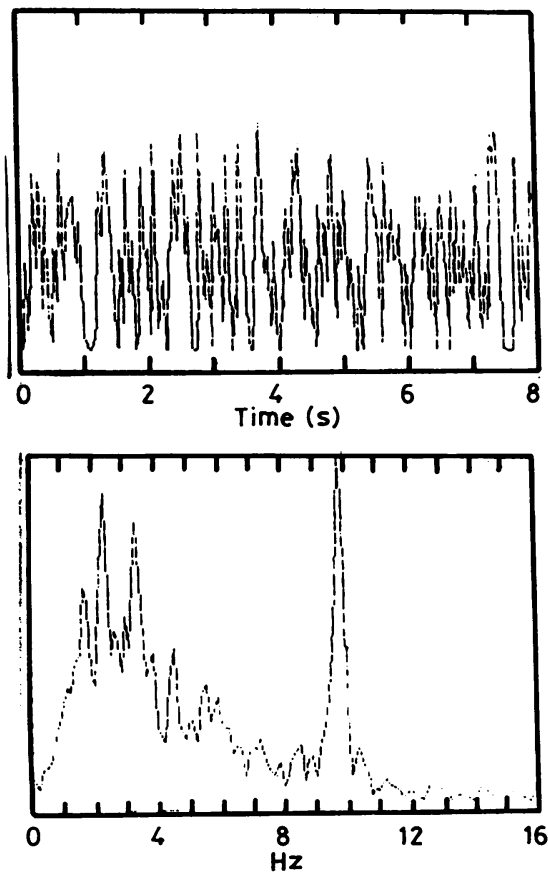

Fig 7 Two cases of low brain stem lesions associated with tremor. Sensitivity $25 \mathrm{~g}$. (a) $B G$, post concussional brain stem syndrome. Right index finger eye open. Tremor amplitude at $1.83 \mathrm{~Hz} 1.73 \mathrm{~g}$. (b) MB, brain stem schwannoma. Left index finger eyes shut. Tremor amplitude at $9.75 \mathrm{~Hz} 7 \cdot 2 \mathrm{~g}$. 
There was the opportunity to study patient MB rather more than others. She had distinct tremor frequencies bilaterally between 9 and $12 \mathrm{~Hz}$. Performance of the task with eyes shut tended to enhance the tremor, partly because the slower frequency non-pathological tremor was then reduced. Addition of 20 and $50 \mathrm{~g}$ weights to the index finger had no effect on the tremor frequency but did slightly increase its amplitude. As the maintained force was reduced from $80 \mathrm{~g}$ to $25 \mathrm{~g}$ to $5 \mathrm{~g}$ and then $2.5 \mathrm{~g}$ so the frequency of tremor reduced, (table 6). The change may be related to the amplitude of tremor since larger oscillations are likely to be slower, suggesting that in this centrally generated tremor some influence is exerted by peripheral factors. In this patient following removal of most of the tumour mass the task was repeated. The fast frequency tremor was completely absent, (fig 8).

\section{Discussion}

The tremors associated with cerebellar lesions have been divided into cerebellar kinetic tremor, (tremor with movement), and cerebellar postural tremor, (beginning in the outstretched limb after a few seconds). ${ }^{1 b^{89}}$ Kinetic tremor is considered to be associated with damage to the cerebellum, ${ }^{10}$ or cerebellar outflow tracts in particular to the dentate nucleus, red nucleus or thalamus. ${ }^{8}$ The frequency of kinetic tremor has been suggested to be a $3-5 \mathrm{~Hz}$ and cooling of the dentate has led to tremor with this frequency in animals. ${ }^{11} 12$

The frequencies of postural tremor have not received so much attention. It has been described as being found in the presence of large amplitude kinetic tremor. ${ }^{9}$ The present tremor, only being elicited by an isometric holding task of small forces, may be therefore a slightly different sort of tremor, more similar to that described by Holmes, ' (and see below).

Although tremor was measured at the finger tip, and particularly across the metacarpophalangeal joint, it was not always confined to the finger. With the high amplitude and lower frequency tremors associated with high brain stem and "red nucleus" lesions then tremor was present throughout the limb. However in those cases in which tremor was not seen except during the task, then it was the experience that it was seen only in the fingers.

\section{a. Tremor with cerebellar hemisphere lesions.}

In the present study tremor was seen bilaterally in lesions of the cerebellar hemispheres when the clinical signs were unilateral and the CT scan showed unilateral disease. The frequencies of tremor were at the low end $5 \mathrm{~Hz}$ but could reach $9-10 \mathrm{~Hz}$ in some cases. In those with clinical tremor, about half the sample, the frequencies were 5-7 Hz. Faster frequen- cies of tremor tended to be continuations of the tremor profile rather than separate peaks.

Although cerebellar tremor has been considered to be expressed in more proximal muscles (see introduction), there is also tremor generated in distal ones. Holmes ${ }^{16}$ wrote that the proximal and distal segments of the limb are equally affected. He also described how cerebellar postural tremor was seen during tasks which require delicacy and precision, for example pencil sharpening. ${ }^{\text {a }}$

\section{$b$. The effect on finger stability of cerebellar hemisphere lesions with clinical past-pointing.}

In his section on static tremor Holmes ${ }^{12}$ wrote that, "if a patient with a unilateral lesion holds both arms extended horizontally in front of him, ... the limb of the affected side may at first maintain its attitude as steadily as its fellow. Indeed for a time it may appear even more steady, since the fine vibratory tremor that is commonly observable in the normal arm when it is extended is often absent in the affected limb".

We also found an asymmetry in this perturbation. However, somewhat surprisingly the effect was a decreased stability contralaterally rather than an increased stability ipisilaterally, when compared with normal controls. This effect was only seen in those patients with kinetic limb signs of pastpointing.

Brodal $^{13}$ noted that with his own right middle cerebral CVA there was, in addition to a profound left hemiparesis, a temporary deficit in fine motor tasks in the right hand. Writing for instance was clumsier. He suggested that this might be due to a cerebellar effect which was contralateral and cited evidence of cerebrocerebellar and cerebellospinal connections which might underlie this.

It has been found previously that in patients with cerebellar lesions and problems with fast movements, slow smooth movements may be better preserved, ${ }^{14}$ supporting Kornhuber's theory ${ }^{15}{ }^{16}$ that the cerebellum may be involved in fast movement and the basal ganglia in smooth ramp movement. In the present task involving no movement, that finger stability was normal ipsilaterally to cerebellar lesions with fast movement deficits is compatible with these theories.

There was a tendency for the amplitude of tremor to be less in normal subjects with the eyes shut rather than open, because of the phase lag between strain gauge and milliammeter movements. This was also the case in the cerebellar lesions. However, the relative reduction in instability on eye closure was greater than normal for the ipsilateral side than for the contralateral side. In patients with past pointing at a macroscopic level on clinical testing there may be pastpointing at the microscopic level during visually lead isometric tasks which is revealed by the test. This asymmetery in stability also suggests that during the 
task control of motor output involved a visuocerebellar component, in agreement with neuroanatomical and physiological evidence reviewed by Stein. ${ }^{4}$

The fact that with cerebellar lesions finger stability is altered during isometric tasks at the fingers suggests that the cerebellum is not solely involved in the larger preprogrammed proximal movements. Holmes ${ }^{16}$ also described how buttoning up of clothes or in musicians playing of the piano or flute could be disturbed even when movements of the arm were apparently normal to other tests.

\section{c. High brain stem lesions.}

With brain stem lesions high in the pons at the level of the nuclei and output tracts of the Vth, VIIth and VIIth cranial nerves the frequencies of tremor observed by the present method were 5-7 Hz. This agrees with other work on cerebellar kinetic tremor. In the present work tremor was found both ipsilaterally and contralaterally to the clinically affected side, reflecting the closeness of structures within the brain stem.

Recordings were made from two patients with classical rubral tremor. The frequencies of tremor were $2 \cdot 25-3 \cdot 25 \mathrm{~Hz}$, contralateral to the damage. Instability was a factor often greater with the eyes open rather than shut. This large improvement in the absence of visual control has also been observed in patients with cerebellar syndromes in multiple sclerosis, (Cole, et al, unpublished). In some cerebellar disease visually lead movement may become grossly inaccurate with improvement possible only with a switch to non-visual control, perhaps homologous with visual apraxia following posterior cortical lesions.

\section{d. Low brain stem lesions.}

In patients with pontine lesions associated with deficits of the lower cranial nerves and long tract signs as well as cerebellar syndromes the associated tremor was fast, between 8 and $11.6 \mathrm{~Hz}$. In nearly all of these patients no tremor was seen clinically, even when during isometric testing it was a significant component.

Similar frequencies of tremor have been described in animal work following administration of harmaline, an alkaloid. ${ }^{16}$ De Montigny and Lamarre ${ }^{17}$ suggested that the inferior olive and its cerebellar projection might be involved in the generation of the tremor. This tremor apparently survives dorsal root section but is abolished by destruction of the inferior olive. In his review Llinas ${ }^{18}$ suggested that under some abnormal circumstances the olive may indirectly generate tremor itself.

In the present study it is obvious that precise localisation in the brain stem of the structures compromised by the lesions is not possible. However, it is of interest that lesions in the region of the olive in man may be associated with fast tremor and that in one patient decompression abolished the tremor dramatically.

The relationship between finger stability and tremor found with unilateral cerebellar and cerebellar tract lesions is shown diagrammatically in fig 9 . The only

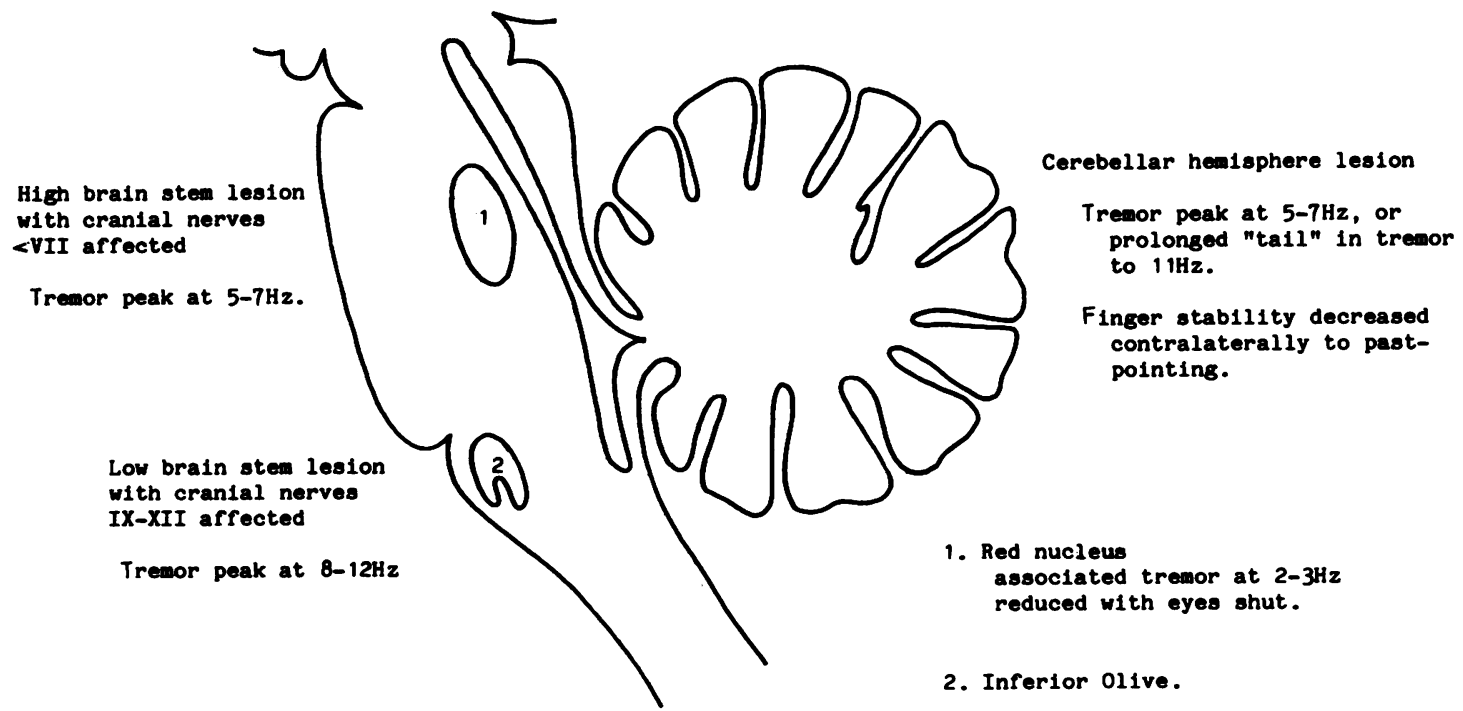

Fig 9 Diagram to show the relation between site of lesion and abnormality of finger stability and tremor. 
tremor which may be specific for a specific site is the fast subclinical tremor associated with low brain stem lesions.

The present technique has proved to be a simple and reliable measure of clinical tremor and of asymmetries in motor control to the finger. It can also reveal subclinical tremor, which may be useful in situations where tremor is claimed but not observed and in showing subclinical abnormalities. To the clinical description of cerebellar tremor might be added the patterns of stability and tremor which occur during tests which stress motor control to the fingers. These are not simply neurophysiological tricks since the patients complained of difficulties with manipulation which previously could not be quantified.

We are grateful to the neurologists and neurosurgeons of the Wessex Neurological Centre for allowing us to perform the test on their patients and to Dr E H Burrows for neuroradiological assessment.

\section{References}

1 Holmes G. The Croonian Lectures on the clinical symptoms of cerebellar disease. Lecture $I^{a}$, Lancet, 1922;i:1177-82, Lecture II ${ }^{b}$ Lancet, 1922;i:1231-7, Lecture III', Lancet, 1922;ii:59-65, Lecture IV ${ }^{\mathrm{d}}$, Lancet, 1922;ii:111-5.

2 Gilman S, Bloedel JR and Lechtenberg R. Disorders of the Cerebellum. 1981. Philadelphia: FA Davis.

3 Harrison MJG. Neurological skills, Butterworths, 1987.

4 Stein JF. Role of the cerebellum in the visual guidance of movement. Nature, 1986;323:217-21.

5 Cole JD, Philip HI, Sedgwick EM. An effect of unilateral cerebellar lesions involving past pointing on fine finger tremor in man. J Physiol (Lond.) 1985;372:16P.

6 Cole JD, Philip HI, Sedgwick EM. Fast frequency (9$11.5 \mathrm{~Hz}$ ) tremor associated with brain-stem lesions in man. J Physiol (Lond.) 1986;377:19P.

7 Cole JD, Philip HI, Sedgwick EM. The effect of frontoparietal lesions on stability and tremor in the finger. $J$ Neurol Neurosurg Psychiatry (in press).

8 Marsden CD. Origins of normal and pathological tremor. In: Findley LJ, Capildeo R, eds. Movement Disorders: Tremor. London: Macmillan, 1984.

9 Rondot P, Bathien N, Toma S. In: Massion J, Sasaki K, eds. Cerebro-cerebellar Interactions. Amsterdam: Elsevier/North Holland Biomedical Press, 203-30.

10 Gilman S, Carr D, Hollenberg J. Kinematic effects of deafferentation and cerebellar ablation. Brain, 1976; 99:311-30.

11 Cooke JD, Thomas JS. Fore-arm oscillation during cooling of the dentate nucleus in the monkey. Can $J$ Physiol Pharmacol. 1976;54:430-6.

12 Vilis T, Hore J. Effects of changes in mechanical state of limb on cerebellar intention tremor. J Neurophys 1977; 40:1214-24.

13 Brodal A. Self-observation and neuroanatomical considerations after a stroke. Brain 1973;96:675-94.

14 Hallett M, Shahani BT, Young RR. EMG analysis of patients with cerebellar deficits. $J$ Neurol Neurosurg Psychiatry 1975;38:1163-9.

15 Kornhuber $\mathrm{HH}$. Motor functions of cerebellum and basal ganglia: The cerebellocortical saccadic (ballistic) clock, the cerebellonuclear hold regulator, and the basal ganglia ramp (voluntary speed smooth movement) generator. Kybernetik, 1971;8:157-62.

16 Lamarre Y. Tremorgenic mechanisms in primates. In: Meldrum BS, Marsden CD, eds. Advances in Neurology, vol 10. New York: Raven Press, 1975.

17 Montigny C De, Lamarre Y. Rhythmic activity induced by harmaline in the olivo-cerebello-bulbar system of the cat. Brain Res 1973;53:81-95.

18 Llinas R. Rebound excitation as the physiological basis for tremor: a biophysical study of the oscillatory properties of mammalian central neurones in vitro. In: Findley LJ, Capildeo R, eds. Movement Disorders: Tremor. London: Macmillan, 1984. 